\title{
Etnografska neobičnost ili trice: prvi pokušaj sustavnog prikupljanja istarskih narodnih pjesama
}

\author{
Izvorni znanstveni rad \\ Original scientific paper \\ UDK 398.8(497.5-3 Istra:436-89)
}

\begin{abstract}
Članak je posvećen neuspješnom pokušaju prikupljanja narodnih pjesama na prostoru Porečke i Pulske biskupije, potaknutom namjerom austrijskih vlasti da se na Velikoj izložbi u Londonu 1851. Habsburška Monarhija predstavi zbirkom koja bi odražavala etničku šarolikost višenacionalnog Carstva. Porečki biskup Antonio Peteani, na zamolbu austrijskog etnografa i statističara Karla von Czoernig-Czernhausena, obratio se istaknutim pripadnicima svećenstva od kojih se mogla očekivati naklonjenost navedenoj zamisli. Pristigli negativni odgovori koji se čuvaju u porečkom biskupijskom arhivu zanimljivo su svjedočanstvo o stavu obrazovanih pojedinaca spram pučke kulture.
\end{abstract}

Ključne riječi: istarske narodne pjesme, Karl von Czoernig, Antonio Peteani, Petar Stanković, Antonio Facchinetti, Andrea Rocco

Počer očetkom 2013. navršilo se točno stotinu godina otkako je Giuseppe Vidossich, lingvist i plodni proučavatelj pučke kulture, na stranicama koparskog lista Pagine Istriane objavio omanji, ali prilično zanimljiv članak o zaboravljenom pokušaju prikupljanja istarskih narodnih pjesama koncem 1850. i početkom 1851. godine (Vidossich 1913). Istražujući rukopisnu ostavštinu barbanskog kanonika Petra Stankovića, početkom dvadesetog stoljeća pohranjenu u pulskoj Gradskoj knjižnici (Biblioteca comunale di Pola), Vidossich je naišao na intrigantan dopis porečkog i pulskog biskupa Antonija Peteanija ",istarskom Plutarhu“ i neočekivano intoniran odgovor što je iz Barbana upućen porečkom Ordinarijatu. Potaknut mogućnošću neočekivanog otkrića, istraživački je nerv nagnao Vidossicha da pokuša produbiti spoznaje uvidom u porečki biskupijski arhiv, zbog nedovoljne sređenosti građe nedostatno iskoristiv tada, kao i stoljeće kasnije. Na koncu, Vidossich je podatke iz Stankovićeve ostavštine uspio tek neznatno proširiti uz pomoć nekoliko šturih rečenica pronađenih u porečkim urudžbenim zapisnicima (Vidossich 1913: 9). Iz teksta izvorno objavljenog sredinom dvadesetog stoljeća, a sadržanog i u zbirci omanjih folklorističkih priloga istog znanstvenika, iako u međuvremenu prezimena preinačenog u Vidossi, razvidno je pak kako ni tijekom više desetljeća istraživačkog rada oskudne podatke iz 1913. nije uspio proširiti novim saznanjima (Vidossi 1960: 462).

Razmjerno opsežno pretraživanje arhivske građe, sačuvane u spomenutom biskupijskom arhivu, provedeno između jeseni 2008. i proljeća 2010. godine s namjerom pronalaska novih izvora za poznavanje djelatnosti biskupa Jurja Dobrile, urodilo je višekratnim, uglavnom nenamjernim, upoznavanjem $s$ dokumentima koji sadržajno i vremenski nemaju veze 
s utemeljiteljem političke i nacionalne emancipacije istarskih Hrvata, ali pružaju itekakav poticaj i podlogu znanstvenom radu usmjerenom proučavanju raznorodnih pitanja povezanih s poviješću istarskog društva tijekom devetnaestog i dvadesetog stoljeća. Među ostalim, riječ je i o nekoliko dopisa koji proširuju Vidossicheve uvide. Nažalost, pokušaji pronalaska povezanih arhivalija u arhivu župe Kanfanar te Biskupijskom (Archivio diocesano di Trieste) i Državnom arhivu u Trstu (Archivio di Stato di Trieste) završili su jednako neuspješno kao i prvo istraživanje pred stotinu godina. Stoga je prilog na stranicama što slijede mjestimičnom fragmentarnošću i domišljanjima koja višekratno premošćuju nedostatak pouzdanih podataka srodan članku kojim je čitateljstvo navedenog koparskog mjesečnika upoznato s neuspjelim pokušajem prikupljanja narodnog blaga sredinom devetnaestog stoljeća. Nije pukom frazom želja da prođe manje od stoljeća prije no što kakav istraživač sretne ruke novim spoznajama dopuni zasad poznate činjenice i poveže ih u koherentnu cjelinu.

2.

Koncem listopada 1850. godine, prvi biskup ujedinjene Porečke i Pulske biskupije, Antonio Peteani, primio je iz Trsta dopis pročelnika Odsjeka pri Ministarstvu trgovine i ministarskog povjerenika za Središnju pomorsku vladu (Sektionschef in Handels Ministerium und Ministerial Comissar für die Centralseebehorde), vezan uz prikupljanje istarskih narodnih pjesama. Dodatno pojašnjenje nužno je, nastoji li se ukloniti možebitna zbunjenost prouzročena na prvi pogled teško povezivom titulom pošiljatelja i sadržajem pisma. Naime, pri osnivanju Središnje pomorske vlade u Trstu, austrijske su se vlasti oslonile na odavna prokušane sposobnosti Karla von Czoernig-Czernhausena, jednog od važnijih statističara devetnaestog stoljeća, ali i pisca vjerojatno najpoznatijeg djela o etnografiji Habsburške Monarhije (Tonetti 1992: 10).

Povod pismu naznačen je već prvim rečenicama: „Prigodom izložbe u Londonu Ministarstvo trgovine namjerava u C. kr. državnoj tiskari otisnuti zbirku pjesama austrijskih naroda uz pripadajuće melodije te in kao etnografsku začudnost poslati u London. Prikladno je da Istra, dodirna točka tako mnogo naroda, pritom bude zastupljena. ${ }^{1}$ Manifestacija o kojoj je riječ ušla je u povijest kao „Velika izložba 1851." (The Great Exhibition of 1851), odnosno prva u nizu sličnih manifestacija na kojima su zemlje sudionice nastojale prikazati ponajbolje od vlastitih umjetničkih, obrtničkih ili industrijskih dosega. Iz Czoernigovih je riječi razvidno postojanje zamisli kako bi se Habsburška Monarhija, među ostalim izlošcima, na londonskoj izložbi mogla podičiti onim što je nerijetko predstavljalo otegotnu okolnost pri upravljanju državom: narodnom heterogenošću. Štoviše, tek dvije godine ranije višenacionalni karakter Monarhije bio je, uz sve prisutniju problematiku društvenih odnosa, uzročnikom četrdesetosmaških revolucionarnih previranja koja su oružjem i oktroiranim ustavom samo privremeno prigušena, a nakon razdoblja otvorenog apsolutizma pedesetih godina ostat će neuklonjivim dijelom političkog i nacionalnog života sve do rasapa Austro-Ugarske.

Uvjeren kako su obrazovanje i znanstveni interesi u svakoj zemlji sabrani prvenstveno među svećenstvom te kako Istra i Porečka i Pulska biskupija pri tom nisu iznimka, Czoernig je zamolio biskupa Peteanija da uznastoji među klerom prikupiti narodne pjesme, optimistično predmnijevajući kako su pojedinci iz vlastitih pobuda to već učinili ili barem kako je riječ o lako i brzo savladivom zadatku. Vrijedi svakako istaknuti kako se pri kraju dopisa spominje

\footnotetext{
Arhiv Biskupije Porečke i Pulske (dalje: ABPP), kut. 151G, kat. XVIII/6, br. 585/Pr, 26.10.1850., Dopis Karla von Czoerniga biskupu Peteaniju („Zum Behufe der Ausstellung zu London beabsichtigt das Handels Ministerium eine Sammlung von Liedern der österreichischen Völker sammt den bezüglichen Melodien in der KK Staatdruckerei auflegen zu lassen, und als eine etnographische Merkwürdigkeit nach London zu senden. Es ist angemessen daß Istrien, dem Berührungspunkte so vieler Nationalitäten hierbei vertreten werde.")
} 
do danas slabo istražen istarski svećenik, sredinom devetnaestog stoljeća očito poznat kao vrstan poznavatelj istarskog narodnog stvaralaštva: „Kao žarki promicatelj ovog proučavanja posebno mi je opisan gospodin župnik Marčelja u Lanišću, pri čemu međutim nije meni poznato, pripada li to mjesto istoj biskupiji. " ${ }^{2}$ Kako Lanišće nije pripadalo Peteanijevoj biskupiji, u sačuvanoj korespondenciji nema dodatnih podataka o Jakovu Marčelji, koji je ondje obnašao župničku dužnost gotovo tri desetljeća, baveći se, uz duhovni, kulturnim i prosvjetnim radom (Žmak 2012: 132).

Biskup Peteani ozbiljno je shvatio Czoernigovu zamolbu te se ubrzo obratio svećenicima od kojih se nadao povoljnom odgovoru, zbog reputacije što ih je pratila. Popis Peteanijevih adresata predstavlja stoga uvid u malobrojnu intelektualnu elitu omalene i prilično zapuštene biskupije. Četverac predvodi već spomenuti barbanski polihistor Stanković, a uz njega poziv je upućen svetvinčentskom župniku Antoniju Facchinettiju, kanfanarskom duhovniku Petru Studencu te Rovinjcu Andreji Roccu, također istaknutom svećeniku svojega vremena. Kako su rijetki tekstovi u kojima se navedeni duhovnici navode $u$ istom kontekstu, vrijedi makar pokojom rečenicom pokušati objasniti Peteanijev odabir, oslanjajući se, gdje je to moguće, na riječi samog biskupa.

\section{3.}

Među spomenutim duhovnicima čelno mjesto pripada Stankoviću, neovisno koristi li se kao kriterij intelektualni ugled što ga je uživao među suvremenicima ili brojnost znanstvenih radova posvećenih njegovu životu i djelu (Strčić 2011: 9-33). Umjesto opširnog prepričavanja višekratno skicirane bogate biografije ili razlaganja o ispravnosti bilježenja kanonikova imena i prezimena u hrvatskoj, odnosno talijanskoj inačici, od veće će koristi biti skrene li se pažnja na osobit položaj što ga u literaturi zauzimaju posljednje godine Stankovićeva života. Naime, od sredine četrdesetih godina devetnaestog stoljeća do smrti 1852., očna bolest koja je od ranije mučila barbanskog svećenika u tolikoj je mjeri uznapredovala da se, gotovo potpuno slijep, pri korespondenciji morao oslanjati na tuđu pomoć. Početkom dvadesetog stoljeća, dakle u vrijeme kad nacionalna pripadnost presudno utječe na intelektualni život Poluotoka, a neizostavno i na oblikovanje svojevrsnih panteona napučenih lučonošama patriotske djelatnosti, Stankovićeva mrzovolja što izbija iz nekoliko sačuvanih pisama tumačena je uglavnom kao očit znak nesnalaženja slabovidnog starca, društveno i duhovno izoliranog $u$ istočnoistarskom gradiću, u novim vremenima što su iziskivala nove snage i pregaoce. Nije, dakle, slučajno što prikaz Stankovićeve nezainteresiranosti spram romantičarski obrazovane mlađe generacije, a poimence Michelea Fachinettija (Venturini 1907: 19-20), dijeli mnoge sličnosti s Vidossichevom sažalnom procjenom kako se „Stanković, pritisnut starošću, oboljelih očiju, osamljen u skromnom istarskom gradiću, nije znao zaputiti novim putem, ostao je pozadi.“ (Vidossich 1913: 11). Sedam desetljeća kasnije, povjesničar znatno otvoreniji povijesti senzibiliteta Stankovićevu je mizantropiju poznih godina, međutim, procijenio uklopivši je u prirođenu impulzivnost, što ju nije teško razabrati ni u drugim tragovima Barbančeva karaktera, odnosno na stranicama spisa što ih je sastavljao tijekom prve polovice devetnaestog stoljeća (Bertoša 1984: 245). Kako bilo, iako neosporno upoznat sa Stankovićevim stanjem, biskup Peteani obratio mu se pouzdajući se u njegovu odavna poznatu sklonost sakupljanju i čuvanju vrijednih izvora. ${ }^{3}$

2 Isto („Als ein eifriger Förderer dieses Studiums würde mir insbesondere der herr Pfarrer Marceglia in Lanisce bezeichnet, wobei mir indeß nicht bekannt ist, ob dieser Ort in Hochderen Diocese gehört.")

3 Sveučilišna knjižnica u Puli, Rukopisi, kut. 7, fsc. 8- MTC 474 („,Per corrispondere al desiderio della prefata I. R. Autorità si trova pertanto necessario di rivolgere particolarmente a V. S. M. R. la quale si distinse sempre nel raccogliere cose patrie $\left.(. . .)^{\prime \prime}\right)$ 
Za razliku od Stankovića čije se narodoznanstvo u literaturi ponajčešće ocjenjuje na temelju jedne svatovske pjesme i pripadajuće opaske kako se ova ima pjevati na melodiju narodne „Lipa Mara papar pleve“ (Stancovich 1818: 138-139; Strčić 2011: 145), posve su jasni razlozi koji su porečkog biskupa potaknuli na obraćanje don Antoniju Facchinettiju. Tek koju godinu ranije, točnije između 20. ožujka i 17. travnja 1847., na stranicama tršćanske L'Istrije u više je nastavaka objavljeno njegovo djelo „Degli Slavi Istriani“, koje je doskora prevedeno na hrvatski jezik i objavljeno u Danici horvatskoj, slavonskoj i dalmatinskoj pod naslovom „O istrianskih Slavjanih“ između 10. srpnja i 4. rujna iste godine. Facchinettijevi uvidi u život seljačkoga slavenskog žiteljstva pristupom se potpuno razlikuju od prevladavajuće nezainteresiranosti istarskoga talijanskog građanstva spram ruralnih dijelova Poluotoka (Colli 1985: 200-202; Bertoša 2005: 12). Njegovi zapisi koji obiluju vrijednim i interesantnim detaljima intonirani su izrazito pozitivno, u skladu s romantičarskim predodžbama njegova vremena, a može se pretpostaviti kako je svakodnevica svetvinčentskog župnika i njegove pastve bila ipak nešto grublja i surovija (Milovan 1975: 43-44). Koristan indikator svakako je činjenica kako se novoimenovani biskup Poreča i Pule, Juraj Dobrila tek desetljeće kasnije, prigodom prve vizitacije, doslovce zgrozio zatečenim stanjem i moralnom zapuštenošću u mnogim dijelovima povjerenog mu područja.

Navedeni biskup, u historiografiji prepoznat kao zamašnjak nacionalne integracije među istarskim Hrvatima, u Facchinettiju je pronašao spremnog suradnika pri pokušajima da, koliko je moguće, popravi zatečeno stanje i ojača temelje na kojima su počivale krhke strukture slavenskih seoskih zajednica, kako bi sve prisutniji modernizacijski procesi potakli njihovu kulturnu, političku i nacionalnu emancipaciju, odnosno kako ih uslijed nespremnosti na svakovrsne društvene promjene ne bi dodatno unazadili. Nedaleko od Svetvinčenta, svjetonazorskog pobornika i bezrezervnog pomagača stekao je i u kanfanarskom duhovniku Petru Studencu, čiju je povezanost sa župljanima i upućenost u narodnu kulturu očigledno cijenio i Dobrilin prethodnik Peteani, proslijedivši mu također Czoernigov upit. Vrijedi spomenuti kako šturi izvori o Studenčevoj djelatnosti podupiru biskupovu procjenu, jer je kanfanarski svećenik bio sklon pjesmi kao osloncu komunikacije s pukom, a iz njegova dopisa Gajevoj Danici razabiremo i visoko mišljenje o narodnom jeziku: „Jezik svakoga naroda kazalo je njegove unutarnje vrijednosti. Bezstrasni motritelj slavjanskoga glasa pazi u njemu neku izvornu primiteljnost svih najblagodatniih izvrstnostih; i čini mu se, kao da darežljivi samodržac svijeta u babilonskom jezikah smutjenju, kada jednom dijelu jafetovih sinovah slavjansko narečje izruči, usipao je u ovo najveći dio jezika, odprie u zemaljskom raju kraljujućega. I do istine, tolika je naravna moć našega govora, i takov ima onomatopoetički značaj, da što ti poslovni čovjeka život djelom kaže, to slavjanska riječ zvukom znači" (Studenac 1844: 3).

Odabranu četvorku zaključuje Rovinjac Andrea Rocco (1774.-1859.), vjerojatno najmanje poznat današnjem čitatelju. Riječ je o dugogodišnjem rovinjskom župniku, čiji je istaknuti položaj najlakše iščitati iz imenovanja počasnim kanonikom porečke katedrale 1843. godine. Osim kao duhovnik, na vjersku je praksu rovinjskih župljana utjecao kao glazbenik i kompozitor (Di Paoli Paulovich 2011: 37-38). Ne čudi stoga zaključak Peteanijevog dopisa u kojem izrijekom navodi kako je, želi li se udovoljiti željama austrijskih vlasti „neophodno obratiti se kleru biskupije i posebno Vašem svijetlom gospodstvu kojeg, kako zbog upućenosti u glazbu tako i zbog ljubavi Rovinjaca spram čuvanja i ponavljanja narodnih pjesama, držimo s punim pravom sposobnijim od bilo koga odgovoriti izloženom upitu. ${ }^{\text {“4 }}$

ABPP, kut. 151G, kat. XVIII/6, br. 585/Pr, 29.10.1850., dopis biskupa Peteanija Andreji Roccu („Per corrispondere al desiderio della prefata imp.reg.Autorità si trova pertanto necessario di rivolgersi al Clero della Diocesi ed a V. S. Ilma. particolarmente, la quale tanto per le cognizioni in musica, quanto per l'amore su Rovignesi di 
Učinivši tako najviše što je mogao, biskup Peteani nije dugo iščekivao odgovore, jer je prvi pristigao već sredinom studenoga 1850., a posljednji početkom veljače 1851. godine.

4.

Najbrži u odgovoru bio je najstariji među pozvanima, Petar Stanković, čiji je dopis stigao na adresu porečkog Ordinarijata već 15 . studenoga. Petnaestak redaka odaslanih iz Barbana bez sumnje predstavljaju prilično razočaranje $s$ etnomuzikološkog gledišta jer ne donose nijedan precizniji podatak o onodobnoj situaciji na terenu Barbanštine kad je riječ o narodnim napjevima, ali imajući u vidu ranije spomenute okolnosti u kojima su sročeni, predstavljaju iznimno poticajan prilog promišljanju o posljednjim Stankovićevim godinama. Vrijedi ih stoga prenijeti u cijelosti.

„Od svoje rane mladosti, potaknut ljubavlju spram domovine, predao sam se prikupljanju svega što mi je moglo dopasti ruku ili osvanuti pred očima, što se moglo odnositi na nju, kako među veličanstvenim starinama, tako i u vezi s poviješću, znanošću, umjetnošću, agronomijom, geologijom te drugim prirodnim znanostima; ali nikad prikupljanju narodne poezije na nijednom jeziku, niti dijalektu pokrajine, nemajući tijekom čitavoga dugog tijeka života nikakvu sklonost takvim tricama; stoga ni u kojem pogledu ne mogu udovoljiti upitu Visokog Ministarstva. Vjerujem, nadalje, kako nitko to ne može provesti, jer nije dovoljno zapisati pjesme, već bi valjalo da neki glazbeni vještak posluša pjevnu harmoniju i ritam svake pojedine te ih naznači glazbenim znakovljem za svaki dijalekt. ${ }^{\text {"5 }}$

Kako je Giuseppeu Vidossichu bio dostupan tek koncept navedenog pisma, u svojoj se kratkoj analizi zadržao isključivo na sadržaju, podcrtavajući središnji dio, odnosno Stankovićevo odbijanje da na jednak način vrednuje ozbiljan znanstveni rad kojem je posvetio život i pučke "tričarije“. Doista, omaleni i prilično izolirani Barban nije bio mjesto kojim bi strujao duh novog vremena, znatno naklonjeniji narodnom geniju, a od vremešnog i slijepog kanonika zasigurno se nije moglo očekivati da iz korijena izmijeni vlastiti pogled na svijet, posebice ne u pogledu stanovništva što ga je okruživalo i pripadajućih mu napjeva. Uzme li se, pak, u ruke pismo sačuvano u porečkom biskupijskom arhivu, pažnju će prije svega zaokupiti detalj koji, barem vizualno, dominira Stankovićevom korespondencijom sastavljanom uz tuđu pomoć. Kao što je pri osvrtu na srodan kanonikov dopis iz iste godine privukao pažnju Miroslava Bertoše u tolikoj mjeri da ga je u faksimilu prenio na koncu članka (Bertoša 1984: 250), i u ovom se pismu ističe Stankovićev potpis - drhtave i grbave tri riječi koje otkrivaju fizičku nemoć starca koji se, međutim, još nije predavao i u intelektualnom pogledu. Tjelesna je slabost tim više u opoziciji spram spremnosti na obranu dostojanstva vlastitog rada pa će se čitatelj kojeg početak Stankovićeva pisma podsjeti na prve Faustove riječi, također posvećene razgranatim učenjačkim aktivnostima kojima je podredio život, dobrza uvjeriti kako Barbanac sa slavnim likom njemačke književnosti nije dijelio i rezignaciju. Uvjeren u nespojivost znanstvenog rada i dokone razbibrige slabo obrazovanog naroda,

conservare e ripetere canti nazionali, riteniamo a tutta ragione più a portata d'ogni altro a corrispondere alla su esposta ricerca.")

$5 \quad$ ABPP, kut. 151G, kat. XVIII/6, br. 711/Pr, 29.11.1850., odgovor Petra Stankovića biskupu Peteaniju datiran 15.11.1850. (,Sino dalla mia prima gioventù, animato dall' amore di patria, io mi prestava a raccogliere tutto ciò che mi poteva pervenire alle mani, o presentarsi agli occhi, che riguardar potesse la medesima, tanto nelle antichità monumentali, come nella parte storica, scientifica, artistica, agronomica, geologica, ed altre scienze naturali; ma non giammai nella raccolta di poesie popolari in nessuna delle lingue, nè in alcun dialetto della provincia, non avendo io per tutto il lungo corso della mia vita avuta alcuna inclinazione per queste bagatelle; quindi non posso sodisfare in modo alcuno all' inciesta dell' Eccelso Ministero. lo credo poi che da nessuno potrà ciò esser eseguito, mentre, non basta trascrivere le canzoni, ma converrebbe che un maestro di musica ascoltasse l' armonia e ritmo del canto di ciascheduna, e le segnasse con note musicali in ciascun dialetto.") 
kanonik Stanković tek se udostojao ovlaš napomenuti kako bi i prikupljanje narodnih pjesama, poduhvati li ga se netko skloniji takvoj djelatnosti, trebalo provesti znatno studioznije od pukog zapisivanja tekstova.

Između Stankovićevog i sljedećeg odgovora protekla su dva i pol mjeseca, jer Antonio Facchinetti, vlastitoj skepsi usprkos, nije olako shvatio molbu Ordinarijata: „Tijekom po prilici dvadeset godina koliko se nalazim u ovoj župi, nikad nisam uspio otkriti kakvu narodnu pjesmu koja bi zavrijedila pažnju obrazovanih. Kako bih ispunio želju ovog Svijetlog Ordinarijata, pisao sam raznim mojim istarskim poznanicima kako bi mi dojavili kakvu istarsku narodnu pjesmu, slavensku ili talijansku, ali je dosad moja potraga ostala jalovom, a nemam, govoreći pravo, ni nade kako u Istri, čiji su sadašnji stanovnici najvećim dijelom pridošli s raznih strana Europe, postoje narodne pjesme u punom smislu riječi. " 6

U Facchinettijevu dopisu najzanimljivije su posljednje rečenice koje upućuju na rasprostranjenost predodžbe o šarolikom istarskom stanovništvu sredinom devetnaestog stoljeća. Tek desetljeće kasnije, na prvim zasjedanjima Pokrajinskog sabora Markgrofovije Istre, predstavnici talijanskog građanstva otklonit će mogućnost objavljivanja zapisnika, uz talijanski, i na "slavenskom jeziku“ koristeći kao argument i kulturnu, odnosno jezičnu neujednačenost među istarskim slavenskim stanovništvom. Činjenica kako je borba za jezičnu ravnopravnost postala izuzetno važnim područjem borbe tijekom višedesetljetne političke i nacionalne emancipacije istarskih Hrvata i Slovenaca, kao i neosporno podcjenjivanje slavenskog stanovništva u očima talijanskih intelektualaca i političara koji su pokrajinu promatrali kao, poviješću, kulturom i identitetom, isključivo talijanski prostor, utjecala je na ponešto pojednostavljenu interpretaciju koja dominira hrvatskom historiografijom. Prema potonjoj, naglašavanje razlika među pojedinim dijelovima istarskog stanovništva u desetljećima prije rasplamsavanja nacionalne integracije isključivo je plod interpretatorove neupućenosti ili zlonamjernosti. Facchinettijevu ocjenu, međutim, valja procjenjivati u drugačijem ključu: svetvinčentski župnik, uostalom, ne ističe heterogeni karakter isključivo slavenskog življa, već svoju ocjenu proteže na „najveći dio sadašnjih stanovnika“. Živeći među seoskim stanovništvom, svakodnevno se, primjerice, susretao s nemalim brojem doseljenika iz današnje sjeverozapadne Italije (Ivetac 2003: 24) koji zasigurno nisu bili posve "ujednačeni“ s talijanskim žiteljstvom priobalnih gradića. Vjerojatno bi na sličan način trebalo ublažiti i ocjenu prikaza istarskog stanovništva u već spominjanom Czoernigovom voluminoznom etnografskom djelu. I ondje je, naime, prisutna slika neujednačenog podrijetla koju dodatno usložnjavaju „,kroatizirani i srbizirani Slovenci i slovenizirani Hrvati, također i kroatizirani Vlasi, isto tako talijanizirani Hrvati što su dijelom i sami zaboravili svoj materinji jezik (na zapadnoj obali), potom kroatizirani Talijani kod kojih je ovo također slučaj (u unutrašnjosti), konačno neko miješano pučanstvo čija je nošnja talijanska, njihovi običaji slavenski, njihov jezik nekakva mješavina srpskih i talijanskih riječi“ (Czoernig 1857: IX). Czoernigov opis, premda korišteno nazivlje višekratno unosi zabunu, ne bi trebalo olako odbacivati. lako sam autor nije iz prve ruke poznavao istarske prilike, o njima ga je podrobno izvijestio neimenovani „poznavatelj istarskih govora" koji je posjetio pojedina mjesta (na istom mj.). Ukratko, Facchinettijeva je ocjena odraz stanja u kojem se predmoderni subetnički identiteti još nisu, pod utjecajem modernizacijskih procesa, pretopili u nacionalne identitete (Blagonić 2012: 149).

ABPP, kut. 151G, kat. XVIII/6, br. 112/Pr, 1.2.1850., odgovor Antonija Facchinettija biskupu Peteaniju datiran 31.1.1851. (,In venti anni circa, che mi trovo in questa parrochia, non mi venne mai fatto di poter scoprire qualche canzone popolare, che meritasse l'attenzione dei colti. Per aderire alle brame di Cod. Illmo Ordinariato, scrissi a diversi miei conoscenti dell' Istria, perchè mi comunicassero qualche canzone popolare istriana, o slava od italiana, ma finore riescirono vane le mie ricerche, nè, a dire il vero, ho speranza, che nell' Istria, i di cui abitanti attuali sono per la maggior parte survenuti da diverse parti dell' Europa, vi sono canti popolari propriamente tali.") 
Iz dopisa barbanskog kanonika i svetvinčentskog župnika razvidno je kako nisu negirali postojanje narodnih pjesama, već ih nisu smatrali dovoljno vrijednima u tekstualnom ni u glazbenom pogledu. Čitajući Stankovićevo pismo početkom dvadesetog stoljeća, Giuseppe Vidossich iskreno je žalio zbog takvog stava, jer se do njegovog vremena društveni život istarskog stanovništva umnogome izmijenio, što se odrazilo i u promjeni stava spram narodnih pjesama koje se više nisu pjevale, nego ih se uz napor prisjećala tek pokoja vremešnija osoba (Vidossich 1913: 10). Moguće je tek nagađati koliko bi ga rastužio jezgroviti odgovor što ga je rovinjski svećenik Andrea Rocco odaslao Ordinarijatu početkom veljače, strogo ocjenjujući kako se „u ovim krajevima ne čuju narodne pjesme; a ono što se ovih dana pjeva među pukom zaslužilo bi najstrože zabrane. ${ }^{17}$

\section{5.}

Nažalost, rukovet sačuvanih pisama u porečkom arhivu ne sadrži i dopis Petra Studenca, a nije sačuvan ni u arhivu župe Kanfanar. Iz urudžbenog je zapisnika moguće tek doznati kako je negativan odgovor pristigao u Ordinarijat 5. veljače 1851., a dva tjedna kasnije biskup Peteani izvijestio je Czoerniga o neuspjehu zamisli. Koncept biskupova odgovora u prilično je lošem stanju što otežava prohodnost kroz tekst, ali razvidno je kako se pri argumentaciji oslonio na pristigle dopise.

Istraživački senzibilitet za raznovrsne sastavnice istarske pučke umjetnosti, pa tako i za narodne pjesme, urodio je prvim zbirkama već tijekom druge polovice devetnaestog stoljeća, a razmjerno povlačenju tradicijske kulture pred modernizacijskim naletima rasla je pažnja što se poklanjala ubrzano nestajućim fragmentima prošlosti. Na navedenom bi tragu možda, kao suprotnost omalovažavajućem stavu izraženom kroz dopise istarskih duhovnika, najprimjerenije bilo istaknuti nedavno pokretanje Centra za nematerijalnu kulturu Istre. Ipak, s dovoljne vremenske udaljenosti, arhivski fragmenti na kojima se temelji ovaj članak poticajan su prilog promišljanju o mentalnim obzorima istaknutih pripadnika klera u omalenoj, rubnoj i prilično nerazvijenoj biskupiji sredinom devetnaestog stoljeća.

\section{POPIS LITERATURE}

\section{BERTOŠA 1984}

Miroslav Bertoša, „Frammento di una autotestimonianza (Pietro Stancovich nel 1850 - par lui même)", Atti del Centro di ricerche storiche di Rovigno, sv. XIV, Rovinj 1983.-'84., 245-250.

\section{BERTOŠA 2005}

Miroslav Bertoša, „Od 'naroda bez povijesti' do povijesnog naroda«, u: D. A. Facchinetti, $O$ istarskim Slavenima, Labin 2005., 5-14.

\section{BLAGONIĆ 2012}

Sandi Blagonić, Od Vlaha do Hrvata, Zagreb 2012.

\section{COLLI 1985}

Carla Colli, „Degli Slavi istriani di don Antonio Facchinetti", Atti del Centro di ricerche storiche di Rovigno, sv. XV, Rovinj 1985., 199-233.

\section{CZOERNIG 1857}

Karl Freiherrn von Czoernig, Etnographie der Oesterreichischen Monarchie, sv. I, Beč 1857.

\section{PAOLI PAULOVICH 2011}

David Di Paoli Paulovich, Cosi Rovigno canta e prega a Dio, Rovinj 2011.

\footnotetext{
ABPP, kut. 151G, kat. XVIII/6, br. 128/Pr, 6.2.1851., odgovor Andreje Rocca biskupu Peteaniju datiran 1.2.1851. (,(...) si rassegna non sentirsi canzoni nazionali in queste parti; e ciò che viene a questi giorni cantato dal volgo meriterebbe le più severe proibizioni.")
} 


\section{IVETAC 2003}

Just Ivetac, Furlanski i karnjelski zrmani, Pazin, 2003.

\section{MILOVAN 1975}

Ivan Milovan, Savičenta jučer danas, Rovinj 1975.

\section{STANCOVICH 1818}

Pietro Stancovich, „Za pyr ossia per nozze“, Versi, Venecija 1818., 138-139.

\section{STRČIĆ 2011}

Petar Strčić, Petar Stanković. Život $i$ djelo (1771.-1852.), Pula 2011.

\section{STUDENAC 1844}

Petar Studenac, "Nekoje misli o narodnom združenju", Danica horvatska, slavonska i dalmatinska, br. 1, Zagreb 6. siječnja 1844., 2-3.

\section{TONETTI 1992}

Maria Tonetti, "Carl Czoernig: la vita e le opere", Karl Czoernig fra Italia e Austria, Gorica 1992., 1-16.

\section{VENTURINI 1907}

Domenico Venturini, „Il canonico Pietro Stancovich, Michele Fachinetti e l'Istria del Kandler", Pro Esposizione pisinese $d^{\prime}$ arte e fotografia, Trst 1907., 19-23.

\section{VIDOSSICH 1913}

Giuseppe Vidossich, „La prima raccolta di canti popolari istriani“, Pagine istriane, br. 1-2, Kopar 1913., 7-11.

\section{VIDOSSI 1960}

Giuseppe Vidossi, „Canzoni popolari narrative dell'Istria", Saggi e scritti minori di folklore, Torino 1960., 460-507.

\section{ŽMAK 2012}

Vladimir Žmak, „Jakov Marčelja, župnik u Lanišću. Narodni preporoditelj, preteča Hrvatskog narodnog preporoda u Istri", Istarska danica 2013., Pazin 2012., str. 132-134.

\section{SAŽETAK}

$\mathrm{U}$ radu je opisan prvi sustavni pokušaj prikupljanja narodnih pjesama u Istri. Koncem 1850., poznati austrijski etnograf Karl von Czoernig-Czernhausen obratio se biskupu Poreča i Pule sa zamolbom da mu pošalje, uz pomoć klera prikupljene, zapise narodnih pjesama. Namjera austrijskih vlasti bila je da se Habsburška Monarhija na međunarodnoj izložbi u Londonu 1851. predstavi, među ostalim, zbirkom narodnih pjesama koje bi posjetiteljima dočarale šarenilo višenacionalnog carstva. Sačuvana pisma von Czoerniga, biskupa Antonija Peteanija, Petra Stankovića, Antonija Facchinettija i Antonija Rocca analizirana su uz oslonac na literaturu posvećenu srodnoj tematici kako bi se ocrtao kontekst u kojem su napisana. Premda se sam pokušaj prikupljanja pokazao neuspješnim, arhivski fragmenti na kojima se temelji ovaj članak poticajan su prilog promišljanju o mentalnim obzorima istaknutih pripadnika klera u omalenoj, rubnoj i prilično nerazvijenoj biskupiji sredinom devetnaestog stoljeća. 


\section{SUMMARY}

\section{Ethnographical Oddity or Trifles: First Attempt of Systematic Gathering of Istrian Folk Songs}

The paper describes the first systematic attempt to collect the folk songs in Istria. At the end of 1850, the famous Austrian ethnographer Karl von Czoernig-Czernhausen addressed the Bishop of Poreč and Pula with the request to send him the written versions of local folk songs, gathered with the help of the clergy. The intention of the Austrian government was to present the Habsburg Monarchy at the Great exhibition in London 1851 through, among other things, a collection of folk songs that would display to the visitors the colourful character of the multinational Empire. The preserved Letters of von Czoernig, bishop Antonio Peteani, Pietro Stancovich, Antonio Facchinetti and Andrea Rocco have been analyzed with reference to the related literature in order to describe their context. Although Czoernig's attempt itself proved unsuccessful, the archival fragments on which this article is based present an inspiring contribution to the reflections on the mental horizons of the prominent members of the clergy in a smaller, peripheral and rather undeveloped Diocese in the midnineteenth century.

Keywords: Istrian folk songs, Karl von Czoernig, Antonio Peteani, Petar Stanković, Antonio Facchinetti, Andrea Rocco 